\title{
Towards prevention of acute lung injury: frequency and outcomes of emergency department patients at-risk - a multicenter cohort study
}

\author{
Peter C Hou ${ }^{1,2,3,4,15^{*}}$, Marie-Carmelle Elie-Turenne ${ }^{5,6}$, Aya Mitani ${ }^{3,7,16}$, Jonathan M Barry ${ }^{2,3,17}$, Erica Y Kao ${ }^{13,18}$, \\ Jason E Cohen ${ }^{8,9,19}$, Gyorgy Frendl ${ }^{3,4,7,20}$, Ognjen Gajic ${ }^{10,11,12,21}$ and Nina T Gentile ${ }^{13,14,22}$ On Behalf of US Critical \\ IIIness and Injury Trials Group: Lung Injury Prevention Study Investigators (USCIITG-LIPS 1)
}

\begin{abstract}
Background: Few emergency department (ED) evaluations on acute lung injury (ALI) have been carried out; hence, we sought to describe a cohort of hospitalized ED patients at risk for ALI development.

Methods: Patients presenting to the ED with at least one predisposing condition to ALI were included in this study, a subgroup analysis of a multicenter observational cohort study (USCIITG-LIPS 1). Patients who met ALI criteria within $6 \mathrm{~h}$ of initial ED assessment, received end-of-life care, or were readmitted during the study period were excluded. Primary outcome was frequency of ALI development; secondary outcomes were ICU and hospital mortality.
\end{abstract}

Results: Twenty-two hospitals enrolled 4,361 patients who were followed from the ED to hospital discharge. ALI developed in $303(7.0 \%)$ patients at a median onset of 2 days (IQR 2-5). Of the predisposing conditions, frequency of ALI development was highest in patients who had aortic surgery (43\%) and lowest in patients with pancreatitis (2.8\%). Compared to patients who did not develop ALI, those who did had higher ICU (24\% vs. $3.0 \%, p<0.001$ ) and hospital ( $28 \%$ vs. $4.6 \%, p<0.001$ ) mortality, and longer hospital length of stay ( 16 vs. 5 days, $p<0.001$ ). Among the 22 study sites, frequency of ALI development varied from less than $1 \%$ to more than $12 \%$ after adjustment for APACHE II.

Conclusions: Seven percent of hospitalized ED patients with at least one predisposing condition developed ALI. The frequency of ALI development varied significantly according to predisposing conditions and across institutions. Further research is warranted to determine the factors contributing to ALI development.

\section{Background}

Adult respiratory distress syndrome (ARDS) was first described by Ashbaugh [1] in 1967. Since then, the definition and criteria for this syndrome have evolved. At the 1994 American-European Consensus Conference (AECC), experts agreed to the following terminology: Acute lung injury (ALI) was defined as the acute onset of hypoxemia

\footnotetext{
* Correspondence: phou@partners.org

'Department of Emergency Medicine, Brigham and Women's Hospital, Boston, MA, USA

2Division of Burn, Trauma, and Surgical Critical Care, Brigham and Women's Hospital, Boston, MA, USA

Full list of author information is available at the end of the article
}

$\left[\mathrm{PaO}_{2} / \mathrm{FiO}_{2}\right.$ (partial pressure of arterial oxygen/fractional concentration of inspired oxygen) $\leq 300 \mathrm{mmHg}$ ] and bilateral infiltrates on frontal chest $x$-ray (Figure 1), in the clinical absence of left atrial hypertension (or when measured, pulmonary-artery wedge pressure $<18 \mathrm{~mm} \mathrm{Hg}$ ) [2]. ARDS is the more severe form of ALI with hypoxemia at $200 \mathrm{mmHg}$ or less [2-4]. In the US, approximately 150,000 to 190,600 cases of ALI occur annually, with an associated mortality rate of 38 to $44 \%, 3.6$ million hospital days, and long-term functional disabilities and cost after intensive care unit (ICU) discharge [5-8]. Pathophysiologically, ALI is classically characterized by an increased 


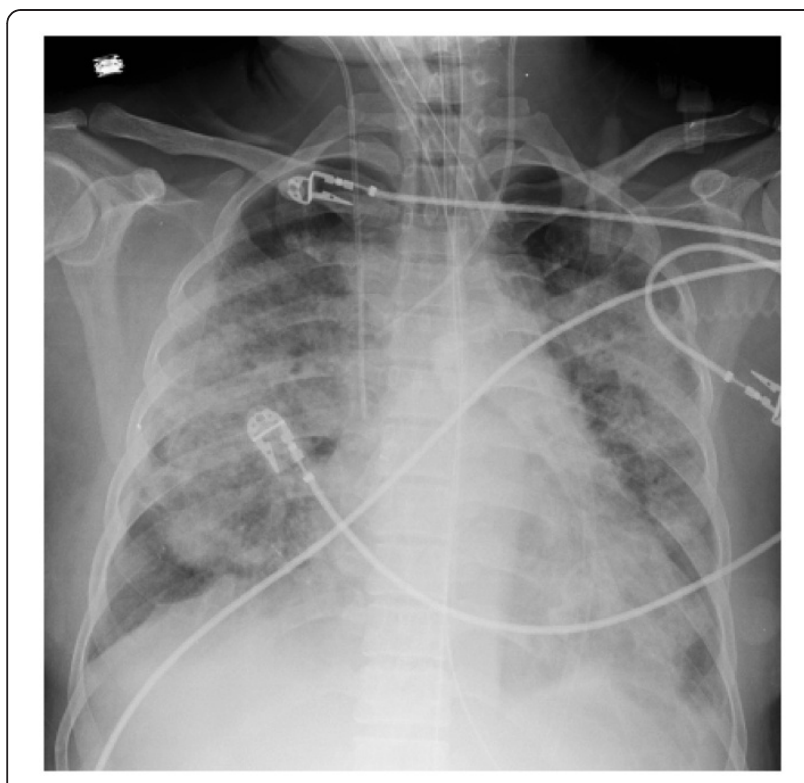

Figure 1 Chest x-ray representing acute lung injury.

permeability of the alveolar-capillary membrane resulting in the influx of protein-rich edema fluid into the air spaces, and etiologies of ALI are myriad, including direct (pulmonary) and indirect (extrapulmonary) causes $[3,4,9]$.

\section{Importance}

Despite numerous randomized controlled trials, a lung protective strategy during mechanical ventilation remains the only therapy shown to improve survival in patients with established ALI [3,4,10-12]. According to the "two-hit" model of ALI development before ALI becomes clinically apparent, a pre-ALI state exists following the first injury to the lungs. The United States Critical Illness and Injury Trials Group-Lung Injury Prevention Study (USCIITG-LIPS 1) investigators focused on defining patient characteristics that would allow us to identify these patients before overt ALI develops. Interventions delivered in this early phase of care can offer potential prevention of ALI. As most clinical studies in ALI have primarily focused on mechanically ventilated patients, insight into a potentially preventable phase of ALI prior to its development is currently lacking $[13,14]$. Data suggest that ALI is rarely present at the time of initial Emergency Department (ED) evaluation; however, a search in top emergency medicine journals yielded many case reports of patients presenting with ALI [15-18]. In reality, many ED patients may have unrecognized ALI and possess many predisposing conditions for ALI development. Recently, a National Heart Lung Blood Institute Workshop Report on future clinical research in ALI recommended to continue the development of strategies to perform ALI prevention trials and observational studies of patients without ALI undergoing prolonged mechanical ventilation [19]. Following the paradigm of trauma team care for major trauma, activation of the cardiac catheterization laboratory team for ST-elevation myocardial infarction and acute stroke teams for ischemic stroke, and early goal-directed therapy for severe sepsis, clinical benefit may be derived from early identification of and preventative interventions for patients at risk of developing ALI.

\section{Goal of this investigation}

We evaluated the frequency of ALI development in atrisk hospitalized ED patients among the study sites, described the predisposing conditions and risk modifiers of ALI development, and determined the attribution of ALI to hospital mortality.

\section{Methods}

\section{Study design}

This is a subgroup analysis of data from a multicenter, observational cohort study, the United States Critical Injury and Illness Trials Group-Lung Injury Prevention Study 1 (USCIITG-LIPS 1) [20,21]. All participating study sites received approval from their respective local institutional review board. The study flow diagram is illustrated in Additional file 1: Appendix 1.

\section{Study setting}

From March through August 2009, 22 centers (20 American and 2 Turkish hospitals) enrolled patients with at least one ALI predisposition admitted from the ED. Patients were enrolled prospectively at 19 study sites and retrospectively at 3 sites.

\section{Selection of participants}

Consecutive adult ED patients admitted to academic and community acute care hospitals were eligible for the study if they presented with one or more a priori defined conditions predisposing to ALI (shock, aspiration, sepsis, pancreatitis, pneumonia, high-risk trauma: traumatic brain injury, smoke inhalation, near drowning, lung contusion, multiple fractures; high-risk surgery: thoracic, spine, acute abdomen, cardiac, aortic vascular; and emergency surgery). Patients were excluded when ALI was present at initial assessment, if they were transferred from an in-patient setting, died in the ED, admitted for comfort or hospice care, or re-admitted during the study period. Hospital admission logs were reviewed to minimize the possibility that patients with predisposing conditions were missed. After identification of atrisk ED patients, they were followed through their hospitalization prospectively in 19 hospitals. In the three hospitals that enrolled retrospectively, investigators 
followed the same protocol and definitions, but data were collected after patient discharge.

\section{Data collection and processing}

Baseline characteristics, including demographics, comorbidities, and clinical variables, were collected during the first $6 \mathrm{~h}$ of initial ED evaluation. Predisposing conditions and ALI risk modifiers were identified and collected. Predisposing conditions were pre-defined, and ALI risk modifiers included: alcohol abuse, obesity chemotherapy, diabetes mellitus, smoking, tachypnea, hypoxemia, oxygen supplementation, hypoalbuminemia, and acidosis.

De-identified subject information was entered at each center into the secure, password-protected NIH-supported web form (REDCap http://www.project-redcap.org). Electronic range checks and validation rules were utilized to eliminate erroneous data entry and artifacts in numeric values. Prior to study initiation at each site, investigators and study coordinators reviewed the definitions of each risk factor (see Additional file 1: Appendix 2) and received mandatory structured online training for ALI assessment. Briefly, in determining if a chest radiograph is consistent with ALI, assessment begins with interpretability of the x-ray followed by evaluation for bilateral opacities generally described as infiltrates consistent with pulmonary edema. Only when the bilateral opacities are not fully explained by non-qualifying opacities (i.e., pulmonary fibrosis) and not limited to the lower lung zones with normal parenchyma above is the chest radiograph consistent with ALI. In addition, a formal training session was provided during the 2009 USCIITG meeting in Nashville, TN. The principal investigators from each site were responsible for data collection and entry, as well as quality control.

\section{Outcome measures}

The primary outcome was the development of AECCdefined ALI during the hospital admission of at-risk ED patients. Secondary outcomes included time to ALI development; proportion and duration of invasive and non-invasive mechanical ventilation; vasopressor requirement; acute renal failure requiring hemodialysis; and ICU and hospital length of stay and mortality.

\section{Primary data analysis}

The Strengthening the Reporting of Observational Studies in Epidemiology (STROBE) guidelines were followed in the design and reporting of this observational study [22]. PCH and AM analyzed the data, which were summarized as number (in percentage) and median (with inter-quartile range). Missing data were coded explicitly as described and handled by using logic expression. Continuous variables were dichotomized at the median. The odds ratios and $95 \%$ confidence intervals were computed from performing logistic regression. Statistical significance was set at 0.05 for regression analysis. Frequency of ALI was calculated per number of ED patients presenting with predisposing condition at the time of hospital admission.

In order to evaluate our secondary outcome measures, we compared hospital and ICU mortality and length of stay between ED patients at risk who developed ALI and those who did not. To determine the mortality burden attributed to the development of ALI, we performed a logistic regression analysis adjusted for the baseline Acute Physiology and Chronic Health Evaluation (APACHE II) score [23]. In addition, we described the utilization and duration of invasive and non-invasive mechanical ventilation, and performed an exploratory analysis comparing patients who did and did not develop ALI with respect to their initial vent settings, specifically tidal volume per predicted body weight, plateau pressure, and positive end expiratory pressure (PEEP). Lastly, we illustrated the frequency of ALI development for each predisposing condition, at hospital day onset, and at each hospital setting. All statistical analysis was performed in SAS 9.2 (SAS Institute, Cary, NC).

\section{Sensitivity analysis}

Sites with retrospective data and extreme frequencies of ALI development were excluded, and a sensitivity analysis of the prospective cohort from the entire ED cohort was performed.

\section{Results and discussion Results}

\section{Characteristic of study subjects}

Twenty-two centers screened 5,992, excluded 166 patients with ALI at admission and other criteria, and enrolled 5,584 patients with at least one ALI predisposition, of which 4,361 patients were admitted from the ED (Figure 2).

\section{ALI Developed within $48 \mathrm{H}$ of Admission in At-Risk Patients and Markedly Increased Mortality}

ALI developed in 303 (7.0 \%) admitted ED patients with a median of 2 days, inter-quartile range (IQR) 2-5 days. Among patients who developed ALI, a subset of 198 $(65.3 \%)$ met the ARDS criteria. The follow-up to hospital discharge was complete in all patients. Baseline characteristics, severity of illness, and predisposing conditions and ALI risk modifiers differed between patients who did and those who did not develop ALI (Table 1). Patients who developed ALI were more likely male and heavier, and had a higher APACHE II score. The majority of patients had all measurements available at the time of hospital admission except for serum albumin $(n=2,423)$ and arterial $\mathrm{pH}(n=1,499)$. As these tests are 
5992 patients with at least one predisposing condition at the time of ED evaluation or hospital admission for elective high-risk surgery

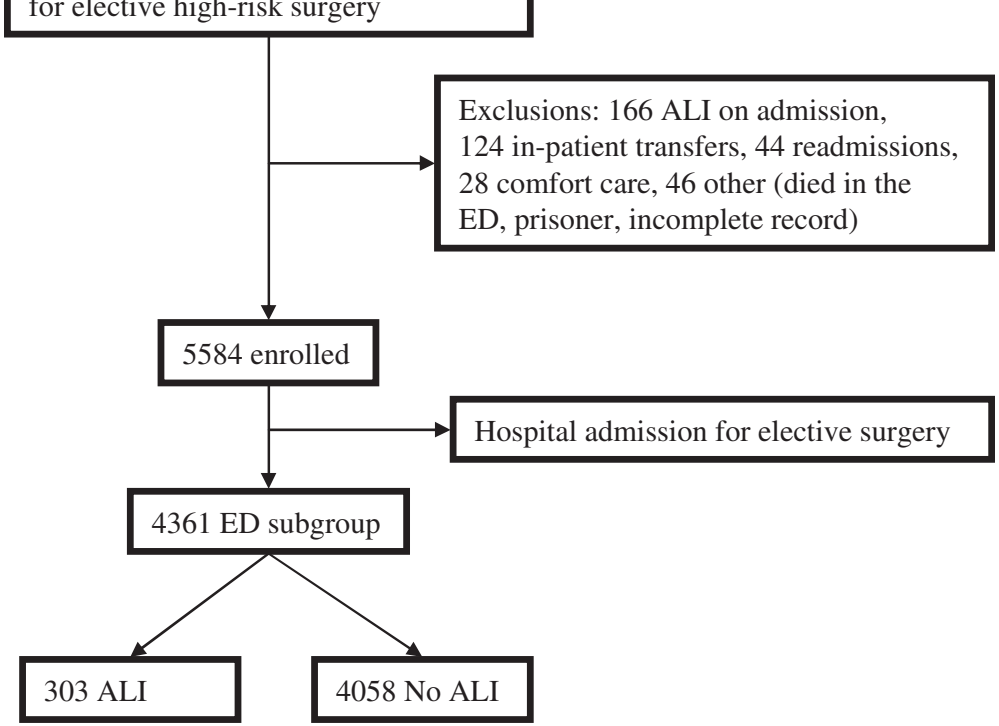

Figure 2 Patient enrollment flow diagram.

usually ordered based on clinical suspicion, missing data were considered normal (i.e., if serum albumin or arterial $\mathrm{pH}$ was not measured, hypoalbuminemia and acidosis were coded as absent), similarly to APACHE score calculation. The odds ratios for ALI development were highest in risk modifiers of tachypnea and a fraction of inspired oxygen $35 \%$ or greater; and in predisposing conditions of aortic vascular, cardiac, and spinal surgeries, near-drowning, and smoke inhalation. However, the numbers of subjects in some of these categories were small compared to others. The frequency of ALI varied according to predisposing condition with the highest rate occurring after emergent aortic surgery (42.9\%) and the lowest rate occurring in pancreatitis (2.8\%) (Figure 3).

Outcome data for the study cohort are shown in Table 2. More than half of the entire cohort and $91 \%$ of patients who developed ALI were treated in the ICU; and $31 \%$ of the entire cohort and $95 \%$ of patients with ALI were either invasively or non-invasively mechanically ventilated. Compared to at-risk patients who did not develop ALI, those who developed ALI were more likely to be ventilated invasively ( $88 \%$ vs $19 \%$ ) and noninvasively (30\% vs $10 \%$ ), respectively. Similarly, comparing to patients who did not develop ALI, those who did had increased resource utilization as reflected in more vasopressor usage (38\% vs $8 \%$ ), a higher percentage of acute hemodialysis requirement (11\% vs $3 \%$ ), and longer ICU (9 vs 2 days) and hospital (16 vs 5 days) lengths of stays. More importantly, patients who developed ALI had increased ICU (24 \% vs $3 \%)$ and hospital ( $28 \%$ vs $5 \%$ ) mortality. When adjusted for severity of illness using the APACHE II score, the development of ALI markedly increased the risk of in-hospital death by more than four-fold [OR 4.45, 95\%CI $(3.23,6.14)]$.

The variation in the frequency of ALI development among the 22 study sites is illustrated in Figure 4. Even after adjustment for each site's APACHE II score, a significant variation in the frequency of ALI development remained. By excluding the one outlier (44\%), the frequency of ALI development varied from 0.7 to $12.8 \%$.

Since the data set is fairly large, the utilization of invasive mechanical ventilation and onset of ALI development were explored. Figure 5 provides a description of ALI development and initiation of invasive mechanical ventilation by hospital day. The majority of patients who developed ALI and who received invasive mechanical ventilation did so within the first 2 days after hospital admission. As illustrated in Figure 6, the majority of patients who developed ALI had initiation of invasive mechanical ventilation on the day of ALI onset. Unfortunately, no data were recorded regarding the exact timing (in hours and minutes) and the reason for initiation of invasive mechanical ventilation with respect to the onset of ALI development. Although relatively few patients developed ALI prior to initiation of invasive mechanical ventilation, many developed ALI a day or more after initiation of invasive mechanical ventilation. 
Table 1 Demographics, predisposing conditions, and risk modifiers in total, no ALI, ALI

\begin{tabular}{|c|c|c|c|c|c|}
\hline Variable & Total $(n=4361)$ & No ALI $(n=4058)$ & ALI $(n=303)$ & OR $(95 \% \mathrm{Cl})$ & P-value \\
\hline \multicolumn{6}{|l|}{ Demographics } \\
\hline Median age (Q1, Q3) & $56.0(41.0,71.0)$ & $56.0(41.0,71.0)$ & $54.0(41.0,67.0)$ & $0.99(0.99,1.00)$ & 0.050 \\
\hline Male, no. (\%) & $2,422(55.5 \%)$ & $2222(54.8 \%)$ & $200(66.0 \%)$ & $1.60(1.26,2.05)$ & $<0.001$ \\
\hline Caucasian $(n=4220)$, no. $(\%)$, & $2608(61.8 \%)$ & $2424(61.8 \%)$ & $184(62.0 \%)$ & $1.01(0.79,1.28)$ & 0.956 \\
\hline Weight $(n=3905)$, median (Q1, Q3) & $76.5(63.5,91.0)$ & $76.0(63.5,91.0)$ & $83.2(69.2,96 . .0)$ & $1.84(1.43,2.37)$ & $<0.001$ \\
\hline PBW( $\mathrm{n}=3551)$, median $(\mathrm{Q} 1, \mathrm{Q} 3)$ & $63.8(64.7,73.0)$ & $63.8(54.6,73.0)$ & $66.1(56.4,75.0)$ & $1.42(1.10,1.84)$ & 0.007 \\
\hline \multicolumn{6}{|l|}{ Admission source $(n=4311)$, no. (\%) } \\
\hline Home & 3,331 (77.3 \%) & $3,125(78.0 \%)$ & $206(68.2 \%)$ & 1.00 & \\
\hline Nursing facility & $338(7.8 \%)$ & $322(8.0 \%)$ & $16(5.3 \%)$ & $0.75(0.45,1.27)$ & 0.002 \\
\hline Outside ED & $440(10.2 \%)$ & $396(9.9 \%)$ & $44(14.6 \%)$ & $1.69(1.20,2.37)$ & 0.253 \\
\hline Other & $202(4.7 \%)$ & $166(4.1 \%)$ & $36(11.9 \%)$ & $3.29(2.23,4.84)$ & $<0.001$ \\
\hline APACHE II (Q1, Q3) & $10.0(6.0,15.0)$ & $9.0(5.0,14.0)$ & $15.0(10.0,21.0)$ & $1.11(1.09,1.13)$ & $<0.001$ \\
\hline \multicolumn{6}{|l|}{ Predisposing conditions } \\
\hline Shock & 395 (9.1\%) & 327 (8.1\%) & $68(22.4 \%)$ & $3.30(2.46,4.42)$ & $<0.001$ \\
\hline Aspiration & $210(4.8 \%)$ & 176 (4.3\%) & $34(1.2 \%)$ & $2.79(1.89,4.11)$ & $<0.001$ \\
\hline Sepsis & $1,806(41.4 \%)$ & $1,684(41.5 \%)$ & $122(40.3 \%)$ & $0.95(0.75,1.21)$ & 0.674 \\
\hline Pancreatitis & $323(7.4 \%)$ & $314(7.7 \%)$ & $9(3.0 \%)$ & $0.37(0.19,0.72)$ & 0.003 \\
\hline Pneumonia & 1,227 (28.1\%) & $1,127(27.8 \%)$ & $100(33.0 \%)$ & $1.28(0.99,1.64)$ & 0.051 \\
\hline \multicolumn{6}{|l|}{ High-risk trauma } \\
\hline Traumatic brain injury & $490(11.2 \%)$ & $445(11.0 \%)$ & $45(14.9 \%)$ & $1.42(1.02,1.97)$ & 0.040 \\
\hline Smoke inhalation & $27(0.6 \%)$ & $20(0.5 \%)$ & 7 (2.3\%) & $4.78(2.00,11.38)$ & $<0.001$ \\
\hline Near drowning & $3(0.1 \%)$ & $2(0.1 \%)$ & $1(0.3 \%)$ & $6.72(0.61,74.27)$ & 0.120 \\
\hline Lung contusion & $188(4.3 \%)$ & $161(4.0 \%)$ & $27(8.9 \%)$ & $2.37(1.55,3.63)$ & $<0.001$ \\
\hline Multiple fractures & $330(7.6 \%)$ & $304(7.5 \%)$ & $26(8.6 \%)$ & $1.16(0.76,1.76)$ & 0.489 \\
\hline \multicolumn{6}{|l|}{ High-risk surgery } \\
\hline Thoracic (noncardiac) & $5(0.1 \%)$ & $4(0.1 \%)$ & $1(0.3 \%)$ & $3.36(0.37,30.12)$ & 0.280 \\
\hline Orthopedic spine & $17(0.4 \%)$ & $13(0.3 \%)$ & $4(1.3 \%)$ & $4.16(1.35,12.85)$ & 0.013 \\
\hline Acute abdomen & $295(6.8 \%)$ & $268(6.6 \%)$ & $27(8.9 \%)$ & $1.38(0.91,2.09)$ & 0.125 \\
\hline Cardiac surgery & $20(0.5 \%)$ & $14(0.3 \%)$ & $6(2.0 \%)$ & $5.84(2.23,15.30)$ & $<0.001$ \\
\hline Aortic vascular & $14(0.3 \%)$ & $8(0.2 \%)$ & $6(2.0 \%)$ & $10.23(3.53,29.68)$ & $<0.001$ \\
\hline Emergency surgery & $339(7.7 \%)$ & $282(7.0 \%)$ & $57(18.8 \%)$ & $3.10(2.27,4.24)$ & $<0.001$ \\
\hline \multicolumn{6}{|l|}{ Risk modifiers } \\
\hline Alcohol abuse & $421(9.7 \%)$ & $381(9.4 \%)$ & $40(13.2 \%)$ & $1.47(1.04,2.08)$ & 0.031 \\
\hline Obesity $(n=3,508)$ & $1,020(29.1 \%)$ & $929(28.6 \%)$ & $91(35.0 \%)$ & $1.34(1.03,1.75)$ & 0.029 \\
\hline Chemotherapy & $158(3.6 \%)$ & $145(3.6 \%)$ & $13(4.3 \%)$ & $1.21(0.68,2.16)$ & 0.520 \\
\hline Diabetes mellitus & $1,042(23.9 \%)$ & $987(24.3 \%)$ & $55(18.2 \%)$ & $0.69(0.51,0.93)$ & 0.016 \\
\hline \multicolumn{6}{|l|}{ Smoking $(n=4,019)$} \\
\hline None & $2,060(51.3 \%)$ & $1,931(51.6 \%)$ & $129(47.1 \%)$ & 1.00 & - \\
\hline Former & $888(22.1 \%)$ & $829(22.1 \%)$ & 59 (21.5\%) & $1.07(0.78,1.47)$ & 0.644 \\
\hline Active & $1,071(26.7 \%)$ & $985(26.3 \%)$ & $86(31.4 \%)$ & $1.31(0.98,1.74)$ & 0.089 \\
\hline $\mathrm{RR}(n=4,137)$, median $(\mathrm{Q} 1, \mathrm{Q} 3)$ & $20.0(18.0,24.0)$ & $20.0(18.0,24.0)$ & $22.0(18.0,27.0)$ & & \\
\hline Tachypnea $(n=4,137)$, no. (\%) & $315(7.6 \%)$ & $269(6.8 \%)$ & $52(18.8 \%)$ & $3.18(2.29,4.40)$ & $<0.001$ \\
\hline $\mathrm{SpO}_{2}(n=4,361)$, median $(\mathrm{Q} 1, \mathrm{Q} 3)$ & $97.0(94.0,99.0)$ & $97.0(94.0,99.0)$ & $95.0(92.0,98.0)$ & & \\
\hline $\mathrm{SpO}_{2}<95 \%(n=4,361)$ & 1,203 (27.6 \%) & $1,076(26.5 \%)$ & $127(41.9 \%)$ & $2.17(1.56,3.02)$ & $<0.001$ \\
\hline $\mathrm{FiO}_{2}(n=4,361)$, median $(\mathrm{Q} 1, \mathrm{Q} 3)$ & $0.2(0.2,0.3)$ & $0.2(0.2,0.3)$ & $0.4(0.2,1.0)$ & & \\
\hline $\mathrm{FiO}_{2}>0.35(n=4,796)$, no. $(\%)$ & $841(19.3 \%)$ & $688(17.0 \%)$ & $153(50.5 \%)$ & $4.92(3.87,6.25)$ & $<0.001$ \\
\hline Albumin $(n=2,423)$, median $(\mathrm{Q} 1, \mathrm{Q} 3)$ & $3.5(2.9,4.0)$ & $3.5(3.0,4.0)$ & $3.2(2.4,3.7)$ & & \\
\hline
\end{tabular}


Table 1 Demographics, predisposing conditions, and risk modifiers in total, no ALI, ALI (Continued)

\begin{tabular}{|c|c|c|c|c|c|}
\hline Hypoalbuminemia $(n=2,423)$, no. (\%) & $945(47.1 \%)$ & $838(45.6 \%)$ & $107(64.5 \%)$ & $2.17(1.56,3.02)$ & $<0.001$ \\
\hline $\mathrm{pH}(n=1,499)$, median (Q1, Q3) & $7.4(7.3,7.4)$ & $7.4(7.3,7.4)$ & $7.3(7.2,7.4)$ & & \\
\hline Acidosis (pH <7.35), no. (\%) & $476(45.9 \%)$ & $364(43.3 \%)$ & $112(56.6 \%)$ & $1.70(1.25,2.33)$ & $<0.001$ \\
\hline
\end{tabular}

PRW: Predicted body weight; RR: respiratory rate; tachypnea $=\mathrm{RR}>30 ; \mathrm{SpO}_{2}$ : oxygen saturation; $\mathrm{FiO}_{2}$ : fraction of inspired oxygen.

\section{Sensitivity analyses}

When data from the two non-US study sites were removed $(n=4,233)$ from the analysis (see Additional file 1: Appendix 3), ALI developed in 266 (6.3\%) patients with a median of 2 days (IQR 2-5 days) after admission to the hospital. The frequency of ALI varied according to predisposing condition with the highest rate of ALI occurring after aortic surgery $(36.4 \%)$ and the lowest rate occurring in pancreatitis (2.9\%). Baseline characteristics, severity of illness, predisposing conditions and ALI risk modifiers, and secondary outcomes remained different between patients who did and those who did not develop ALI. However, there were no significant differences in the group characteristics from the US study sites when comparing to the entire cohort.
In addition, when data from the three retrospective US study sites were removed $(n=3,981)$ from our descriptive analysis (see Additional file 1: Appendix 4), ALI developed in 241 (6.1\%) patients with a median of 2 days (IQR 2-4 days) after admission to the hospital. The frequency of ALI varied according to predisposing condition with the highest rate of ALI occurring after aortic surgery $(40 \%)$ and the lowest rate occurring in pancreatitis $(2.4 \%)$. Baseline characteristics, severity of illness, predisposing conditions and ALI risk modifiers, and secondary outcomes maintained their differences between patients who did and did not develop ALI. However, there were no significant differences in the group characteristics when comparing the prospective US sites and the entire US cohort.

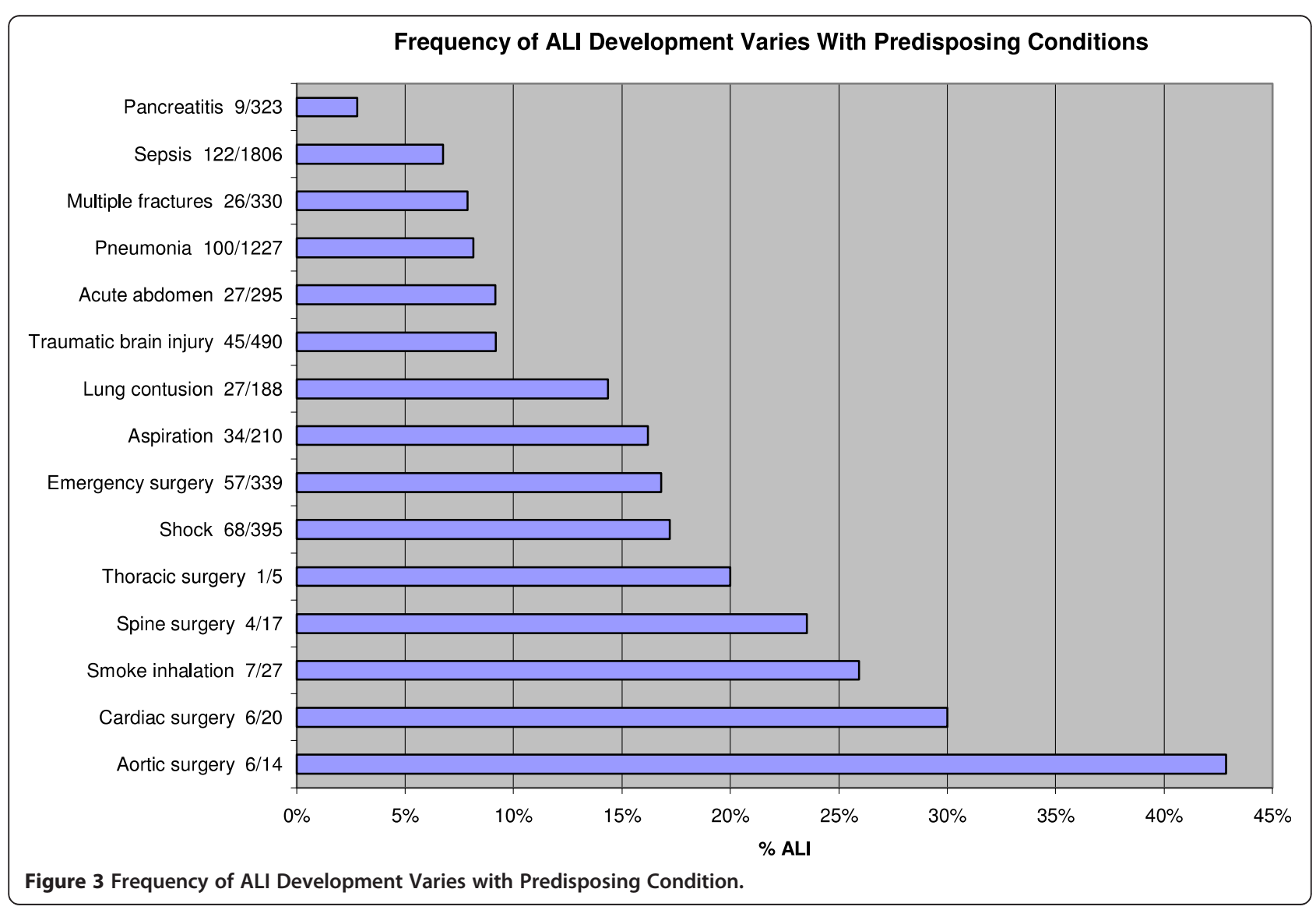


Table 2 Hospital course and outcomes for total, No ALI, and ALI

\begin{tabular}{|c|c|c|c|c|c|}
\hline Variable & Total $(n=4,361)$ & No $A L I(n=4,058)$ & ALI $(n=303)$ & OR $(95 \% \mathrm{Cl})$ & P-value \\
\hline ICU admission, no. (\%) & $2,320(53.2 \%)$ & $2,043(50.3 \%)$ & $277(91.4 \%)$ & $10.50(6.99,15.77)$ & $<0.001$ \\
\hline ICU LOS ( $n=2,320)$, median (Q1, Q3) & $2.0(1.0,5.0)$ & $2.0(0.0,4.0)$ & $9.0(5.0,17.0)$ & $19.12(9.79,37.38)$ & $<0.001$ \\
\hline Hospital LOS ( $n=4361)$, median (Q1, Q3) & $6.0(3.0,10.0)$ & $5.0(3.0,9.0)$ & $16.0(9.0,26.0)$ & $8.60(5.94,12.36)$ & $<0.001$ \\
\hline Vasopressors use, no. (\%) & $448(10.3 \%)$ & $334(8.2 \%)$ & $114(37.6 \%)$ & $6.73(5.20,8.71)$ & $<0.001$ \\
\hline Acute hemodialysis ( $n=4,290)$, no. (\%) & $148(3.5 \%)$ & $115(2.9 \%)$ & $33(11.0 \%)$ & $4.15(2.76,6.23)$ & $<0.001$ \\
\hline ICU mortality, no. (\%) & $194(4.5 \%)$ & $120(3.0 \%)$ & $74(24.4 \%)$ & $10.61(7.71,14.59)$ & $<0.001$ \\
\hline Hospital mortality, no. (\%) & $272(6.2 \%)$ & $188(4.6 \%)$ & $84(27.7 \%)$ & $7.90(5.90,10.56)$ & $<0.001$ \\
\hline Mechanical ventilation $(n=4,223)$ & 1,299 (30.8\%) & $1,013(25.8 \%)$ & $286(94.7 \%)$ & $51.29(30.85,85.28)$ & $<0.001$ \\
\hline Non-invasive $(n=4,146)$, no. (\%) & $470(11.3 \%)$ & $387(10.0 \%)$ & $83(30.1 \%)$ & $3.87(2.93,5.11)$ & $<0.001$ \\
\hline Non-invasive duration $(n=461)$, median $(\mathrm{Q} 1, \mathrm{Q} 3)$ & $2.0(1.0,5.0)$ & $2.0(1.0,5.0)$ & $3.0(2.0,5.5)$ & $1.29(0.73,2.25)$ & 0.379 \\
\hline Invasive $(n=4,228)$, no. (\%) & $997(23.6 \%)$ & $730(18.6 \%)$ & $267(88.4 \%)$ & $33.40(23.27,47.94)$ & $<0.001$ \\
\hline Invasive duration ( $n=932)$, median (Q1, Q3) & $3.0(1.0,8.0)$ & $2.0(1.0,5.0)$ & $8.0(4.0,15.0)$ & $6.53(4.52,9.42)$ & $<0.001$ \\
\hline TV/PBW ( $n=768)$, median (Q1, Q3) & $8.3(7.4,9.5)$ & $8.4(7.5,9.7)$ & $8.1(7.3,9.2)$ & $0.70(0.51,0.96)$ & 0.029 \\
\hline Plateau pressure $(n=435)$, median $(\mathrm{Q} 1, \mathrm{Q} 3)$ & $19.0(16.0,24.0)$ & $19.0(15.0,23.0)$ & $21.0(17.0,27.2)$ & $1.77(1.17,2.69)$ & 0.007 \\
\hline $\operatorname{PEEP}(n=916)$, median (Q1, Q3) & $5.0(5.0,5.5)$ & $5.0(5.0,5.0)$ & $5.0(5.0,8.0)$ & $2.30(1.32,4.01)$ & 0.003 \\
\hline Mode: Volume control & $762(83.9 \%)$ & $561(86.4 \%)$ & $201(77.6 \%)$ & 1.00 & - \\
\hline Mode: Pressure control & $111(12.2 \%)$ & 63 (9.7\%) & 48 (18.5\%) & $2.13(1.41,3.20)$ & 0.010 \\
\hline
\end{tabular}

ICU: Intensive care unit; LOS: length of stay; TV: tidal volume; PBW: predicted body weight; PEEP: peak end-expiratory pressure.

Effects of initial ventilator settings on the development of ALI

Since there is growing evidence to suggest that a lung protective strategy with low tidal volume ventilation may be protective in at-risk patients, we explored the effect of the initial vent setting on ALI development [24,25]. We evaluated the initial tidal volume divided by predicted body weight (TV/PBW in $\mathrm{cc} / \mathrm{kg}$ ) in 768 patients

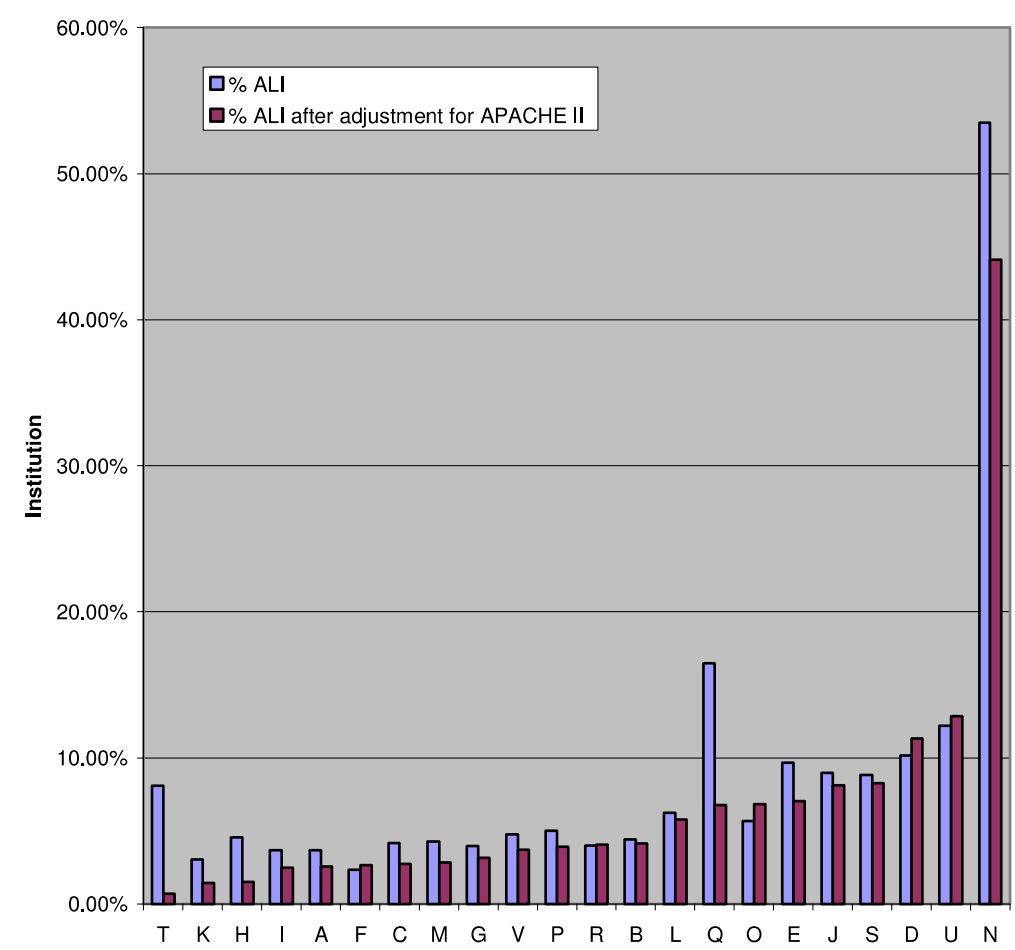

Figure 4 Frequency of ALI Development Varies by Institution. 


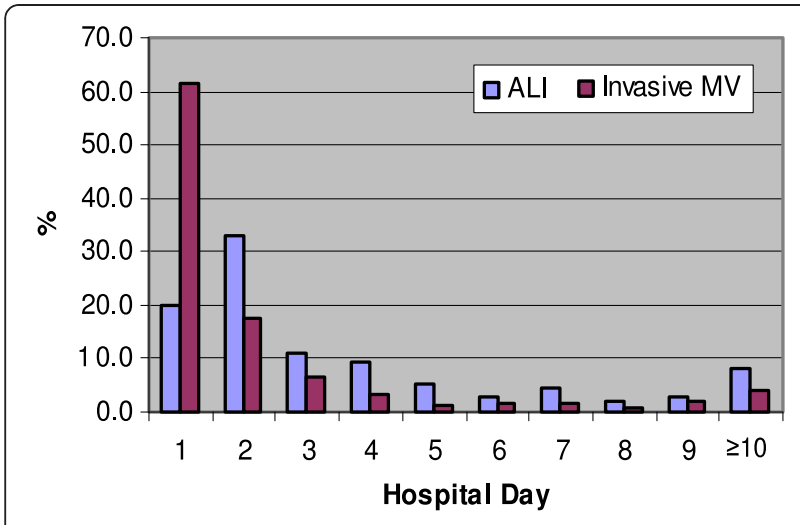

Figure 5 Percentage of ALI Development and Invasive Mechanical Ventilation Onset by Hospital Day.

who underwent invasive mechanical ventilation (Table 2). Comparing those who did not, patients who developed ALI received a significant lower initial TV/PBW [8.1 vs 8.4, OR 0.70 (95 \% CI 0.51-0.96), $p=0.029$ ] but had a significantly higher plateau pressure [21 vs 19 , OR 1.77 (95\% CI 1.17-2.69), $p=0.007]$ and peak end-expiratory pressure (PEEP) [OR 2.30 (95\% CI 1.32-4.01), $p=0.003$ ]. Regarding the mode of mechanical ventilation, a significantly higher proportion of patients who developed ALI was initiated on pressure control ventilation [OR 2.13 (95\% CI 1.41-3.2), $p=0.01]$ and non-invasive ventilation [OR 3.87 (95\% CI 2.93-5.11), $p<0.001$ ] compared to those who did not develop ALI; in contrast, no significant difference was found in those who underwent initial volume control ventilation.

\section{Limitations}

Our study carries the limitations of observational cohort studies and those inherent to clinical research with ALI: inter-observer reliability of portable chest X-ray interpretation, ALI imitators, and consistency in determining exclusion of left atrial hypertension as the principal cause of pulmonary edema [26-28]. We instituted a mandatory structured training in ALI assessment and held the site-principal investigators responsible for

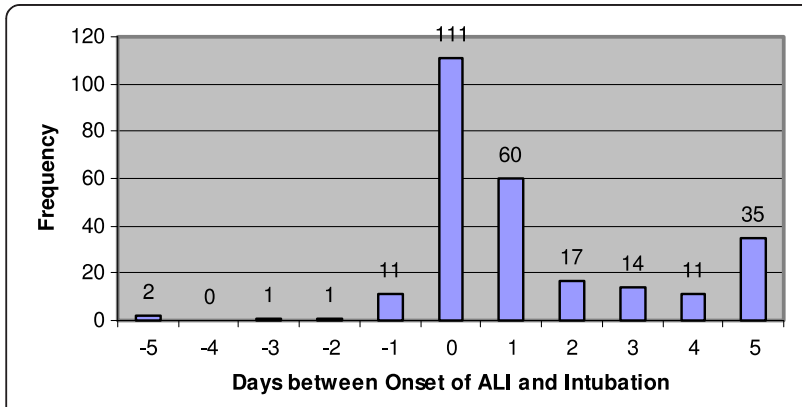

Figure 6 Days between Onset of ALI Development and Invasive Mechanical Ventilation. quality control. These measures were intended to mitigate these limitations.

Regarding the variation in the frequency in ALI development among the study sites, two non-US sites had the highest rate and could be explained by differences in their health-care delivery system, specifically emergency medical care and critical care services, and possibly population and environmental factors. When the data from these two non-US centers were excluded, no significant difference in the frequency of ALI development $(p=0.216)$ was found between the US sites. In addition, the vast majority of patients were enrolled prospectively ensuring close follow-up and reducing the risk of misclassification from medical record review. When data from those centers enrolling retrospectively were excluded, no significant difference in the frequency of ALI development $(p=0.665)$ was found comparing the prospective US sites to the entire US cohort. Hence, although a significant variation in the frequency of ALI development across institutions was found, the US sites and the prospectively enrolling US sites were not significantly different when each subgroup was compared to the entire cohort.

\section{Discussion}

Even though ALI is classified as a rare disease [29], it is a major public health concern. It is, however, unclear how much if variations in initial management of ALIprone patients by emergency physicians contribute to its development. To our knowledge, this is the largest detailed study of a cohort of hospitalized adult ED patients at risk for ALI development. The strengths of this study include the large sample size from a geographically diverse population of patients at both academic and community hospitals. Using routinely available clinical data, we identified ED patients at risk for ALI development early in the course of their illness. The early identification of predisposing conditions and risk modifiers as well as subsequent interventions in the ED and ICU may potentially prevent disease development by minimizing or avoiding secondary insults.

Interestingly, in our study we found that ALI developed with lower frequencies than previously reported following conditions recognized to predispose patients at risk for ALI such as: aspiration, pneumonia, sepsis, and trauma $[30,31]$. This may be explained by the fact that our patients were enrolled early (in the ED) without any signs of ALI (with at least one predisposing factor present) and we excluded those who developed ALI within $6 \mathrm{~h}$ of ED presentation, while those other studies enrolled patients upon ICU admission. Consistent with our findings, a recent study by Ferguson et al. showed that $7 \%$ of patients with sepsis, $2 \%$ of patients with pancreatitis, $10 \%$ of patients with pneumonia, and $15 \%$ 
of patients with witnessed aspiration developed ALI [32]. Similarly, the majority of patients with predisposing conditions never developed ALI, and many were not admitted to the ICU.

Our inclusion criteria required the presence of at least one ALI risk factor at the time of hospital admission, potentially missing the patients who acquire a predisposing condition and received a secondary injury later in the hospital stay. We cannot rule out that a minority of our patients identified as high risk were already progressing to develop full-blown ALI at the time of enrollment, although the exclusion of those who developed ALI within $6 \mathrm{~h}$ of ED presentation intended to minimize this possibility. However, we do believe that earlier identification of such patients would also be of benefit, and could help limit the progression of ALI development and improve patient outcomes by alerting providers to make efforts to limit second-hit exposures. To support this notion, a population-based study in Olmsted County, Minnesota, has recently shown a steady decline in ARDS incidence. This was attributable entirely to a reduced incidence of hospital-acquired ARDS and suggests that recent improvements in prevention, early recognition, and critical care delivery may in part be responsible for this [33].

From Olmsted County's experience, major system changes within the hospital throughout the years were progressively made. These include electronic medical records with computerized order entry to monitor data and institute decision support, restrictive transfusion protocol with leukoreduction and male donor predominant plasma transfusion, respiratory therapy protocol on limiting initial volume according to predicted body weight on all patients, increased staffing of intensivists with 24-h on site, sepsis resuscitation protocols and teams, rapid response teams, standardization of inpatient pneumonia care, and staff education and training. Regarding potential interventions that may affect the development of ALI, a checklist for lung injury prevention (CLIP) has been proposed and developed by experts in the field [34]. The CLIP domains (and elements) consist of routine ICU practices of morbidity prevention and include: respiratory support (lung protective strategies, minimizing oxygen toxicity) $[12,24,25]$; aspiration precautions (rapid sequence intubation, head-of-bed elevation, oral care with chlorhexidine) [35-37]; infection control (early and appropriate antibiotic therapy, source control, prevention of nosocomial infection transmission) [38]; fluid management (early fluid resuscitation in severe sepsis and septic shock, fluid restriction after shock resolution) [39,40]; transfusion management (restrictive red blood cell transfusion threshold, transfusion guidelines for blood products) [40,41]; and communication (validated structured handoffs such as SBAR: situation, background, assessment, and recommendation)
[42]. As a continuum in the care of the critically ill starting in the ED and transitioning to the ICU, all of these domains and many of these proposed elements are being followed to a certain extent, but inconsistently as reflected in our own experiential observations and practice variations. However, such a proposed checklist will require validation for its utility in adherence to best practices and ALI prevention.

\section{Conclusions}

Many ED patients who are hospitalized have risk factors for ALI development. In this cohort, we found $7 \%$ of ED patients with at least one predisposing condition developed ALI, and there is variation in the frequency of ALI development across study sites. In addition, more resources are utilized in patients who do develop ALI, and more importantly, ALI significantly increased the patient's risk of death in the hospital. Hence, is there a role for emergency physicians in the management of patients at risk for ALI development?

Currently, pre-planned ancillary studies are ongoing to explore potential differences in development of ALI at different hospital settings, in different disease-related groups, and their specific treatment modalities. In addition, acute lung injury prevention trials are being proposed. Further research is also warranted to develop a prediction model to identify hospitalized ED patients at risk of ALI development at an early stage in their illness.

\section{Additional file}

Additional file 1: Web files Appendices [43-94].

\section{Abbreviations}

AECC: American-European consensus conference; ALI: acute lung injury; APACHE: acute physiology and chronic health evaluation; ARDS: acute respiratory distress syndrome; CLIP: checklist for lung injury prevention; ED: emergency department; ICU: intensive care units; LIPS: lung injury prediction score; PEEP: positive end expiratory pressure; PBW: predicted body weight; TV: tidal volume; USCIITG-LIPS 1: United States Critical Injury and Illness Trials Group-Lung Injury Prevention Study 1; VALI: ventilator-associated lung injury.

\section{Competing interests}

The STAR Center provided internal funding (Dr. Frendl), research staff, and biostatistical support, Brigham and Women's Hospital, Boston, MA. Dr. Gajic is supported in part by grants from the National Heart, Lung, and Blood Institute HL78743-01A1; National Center for Research Resources 1 KL2 RR024151. Dr. Gentile is supported in part by grants from the National Institute of Neurological Disorders and Stroke 5U10NS059039-04. The rest of the authors have no disclosures or conflict of interest.

\section{Authors' contributions}

PCH, MCE, OG, and NTG conceived the study, designed the review, and supervised the conduct of the review and data collection. GF obtained research funding. $\mathrm{PCH}, \mathrm{AM}$, and $\mathrm{OG}$ extracted and managed the data and performed quality control of the data. AM provided statistical advice on study design, and all authors analyzed the data. PCH drafted the manuscript, and all authors provided significant contributions to its revision. PCH takes 
responsibility for the paper as whole. All authors read and approved the final manuscript.

\section{Acknowledgments}

US Critical Illness and Injury Trials Group: Lung Injury Prevention Study Investigators (see Additional file 1: Appendix 5).

\section{Author details}

'Department of Emergency Medicine, Brigham and Women's Hospital, Boston, MA, USA. ${ }^{2}$ Division of Burn, Trauma, and Surgical Critical Care, Brigham and Women's Hospital, Boston, MA, USA. ${ }^{3}$ Surgical Intensive Care Unit Translational Research (STAR) Center, Brigham and Women's Hospital, Boston, MA, USA. ${ }^{4}$ Harvard Medical School, Boston, MA, USA. ${ }^{5}$ Department of Emergency Medicine, University of Florida College of Medicine, 1329 SW 16th Street, Gainesville FL 32610, USA. ${ }^{6}$ Emergency Department, Shands University of Florida, Medical Center, Gainesville, FL, USA. 'Department of Anesthesiology, Perioperative and Pain Medicine, Brigham and Women's Hospital, Boston, MA, USA. ${ }^{8}$ Department of Emergency Medicine, Albany Medical Center, Albany, NY, USA. ${ }^{9}$ Albany Medical College, Albany, NY, USA. ${ }^{10}$ Division of Pulmonary and Critical Care Medicine, Department of Medicine, Mayo Clinic, Rochester, MN, USA. ${ }^{11}$ Multidisciplinary Epidemiology and Translational Research in Intensive Care (METRIC), Mayo Clinic, Rochester, MN, USA. ${ }^{12}$ Mayo Medical School, Rochester, MA, USA. ${ }^{13}$ Department of Emergency Medicine, Temple University Hospital, Philadelphia, PA, USA. ${ }^{14}$ Temple University School of Medicine, Philadelphia, PA, USA. ${ }^{15}$ Harvard Medical School, Department of Emergency Medicine \& Division of Burn, Trauma, and Surgical Critical Care, Department of Surgery, Brigham and Women's Hospital, 75 Francis Street, Neville House 312-B, Boston, MA 02115 , USA. ${ }^{16}$ Department of Medicine, Stanford Hospitals and Clinics, 300 Pasteur Drive, Room: S102, MC: 5110, Stanford, CA 94305, USA. ${ }^{17}$ Division of Burn, Trauma, and Surgical Critical Care, Brigham and Women's Hospital, 75 Francis Street, Boston, \02115, USA. ${ }^{18}$ Department of Emergency Medicine, Brigham and Women's Hospital, 75 Francis Street, Boston, MA 02115, USA. ${ }^{19}$ Albany Medical Center Emergency Medicine Group, 47 New Scotland Avenue, MC 139, Albany, NY 12208, USA. ${ }^{20}$ Department of Anesthesiology Perioperative and Pain Medicine, Brigham and Women's Hospital, 75 Francis Street, Boston, MA 02115, USA. ${ }^{21}$ Pulmonary and Critical Care Medicine, Mayo Clinic, Old Marian Hall, Second Floor, Room 115, 200 First St. SW, Rochester, MN 5590, USA. ${ }^{22}$ Department of Emergency Medicine, Temple University Hospital, Administrative Office, 10th Floor, Jones Hall, 1316 W. Ontario Street, Philadelphia, PA 19140, USA.

\section{Received: 30 December 2011 Accepted: 1 April 2012}

Published: 27 May 2012

\section{References}

1. Ashbaugh DG, Bigelow DB, Petty $T L$, Levine BE (1967) Acute respiratory distress in adults. Lancet 2:319-323.

2. Bernard GR, Artigas A, Brigham KL, Carlet J, Falke K, Hudson L, Lamy M, Legall JR, Morris A, Spragg R (1994) The American-European Consensus Conference on ARDS. Definitions, mechanisms, relevant outcomes, and clinical trial coordination. Am J Respir Crit Care Med 149:818-824.

3. Ware LB, Matthay MA (2000) The acute respiratory distress syndrome. N Engl J Med 342:1334-1349.

4. Wheeler AP, Bernard GR (2007) Acute lung injury and the acute respiratory distress syndrome: a clinical review. Lancet 369:1553-1564.

5. National Heart and Lung Institute (1972) Task force on problems, research approaches, needs: the lung program. Department of Health, Education, and Welfare, Washington, D.C, pp 73-432, [Publication no. (NIH).

6. Rubenfeld GD, Caldwell E, Peabody E, Weaver J, Martin DP, Neff M, Stern EJ, Hudson LD (2005) Incidence and outcomes of acute lung injury. N Engl J Med 353:1685-1693.

7. Phua J, Badia JR, Adhikari NK, Friedrich JO, Fowler RA, Singh JM, Scales DC, Stather DR, Li A, Jones A, Gattas DJ, Hallett D, Tomlinson G, Stewart TE, Ferguson ND (2009) Has mortality from acute respiratory distress syndrome decreased over time?: A systematic review. Am J Respir Crit Care Med 179:220-227.

8. Herridge MS, Tansey CM, Matte A, Tomlinson G, Diaz-Granados N, Cooper A Guest CB, Mazer CD, Mehta S, Stewart TE, Kudlow P, Cook D, Slutsky AS, Cheung AM (2011) Functional disability 5 years after acute respiratory distress syndrome. N Engl J Med 364:1293-1304.
9. Pugin J, Verghese G, Widmer MC, Matthay MA (1999) The alveolar space is the site of intense inflammatory and profibrotic reactions in the early phase of acute respiratory distress syndrome. Crit Care Med 27:304-312.

10. Salzer WL, McCall CE (1990) Primed stimulation of isolated perfused rabbit lung by endotoxin and platelet activating factor induces enhanced production of thromboxane and lung injury. J Clin Invest 85:1135-1143.

11. Silliman CC, Voelkel NF, Allard JD, Elzi DJ, Tuder RM, Johnson JL, Ambruso DR (1998) Plasma and lipids from stored packed red blood cells cause acute lung injury in an animal model. J Clin Invest 101: 1458-1467.

12. (2000) Ventilation with lower tidal volumes as compared with traditional tidal volumes for acute lung injury and the acute respiratory distress syndrome. The Acute Respiratory Distress Syndrome Network. N Engl J Med 342:1301-1308.

13. Levitt JE, Bedi H, Calfee CS, Gould MK, Matthay MA (2009) Identification of early acute lung injury at initial evaluation in an acute care setting prior to the onset of respiratory failure. Chest 135:936-943.

14. Thakur SJ, Trillo-Alvarez CA, Malinchoc MM, Kashyap R, Thakur L, Ahmed A, Reriani MK, Cartin-Ceba R, Sloan JA, Gajic O (2010) Towards the prevention of acute lung injury: a population based cohort study protocol. BMC Emerg Med 10:8-17.

15. Catchings T, Beamer WC, Lundy L, Prough DS (1985) Adult respiratory distress syndrome secondary to ethylene glycol ingestion. Ann Emer Med 14:594-596.

16. Van Sickle D, Wenck MA, Belflower A, Drociuk D, Ferdinands J, Holguin F, Svendsen E, Bretous L, Jankelevich S, Gibson JJ, Garbe P, Moolenaar RL (2009) Acute health effects after exposure to chlorine gas released after a train derailment. The Am J Emer Med 27:1-7.

17. Wang SQ, Li CS, Song YG (2009) Multiply organ dysfunction syndrome due to tramadol intoxication alone. Am J Emer Med 27:903, e5-7.

18. Wu J, Sheng L, Ma Y, Gu J, Zhang M, Gan J, Xu S, Jiang G (2008) The analysis of risk factors of impacting mortality rate in severe multiple trauma patients with posttraumatic acute respiratory distress syndrome. Am J Emer Med 26:419-424.

19. Spragg RG, Bernard GR, Checkley W, Curtis JR, Gajic O, Guyatt G, Hall J, Israel E, Jain M, Needham DM, Randolph AG, Rubenfeld GD, Schoenfeld D, Thompson BT, Ware LB, Young D, Harabin AL () Beyond mortality: future clinical research in acute lung injury. Am J Respir Crit Care Med 181:1121-7.

20. Cobb JP, Ognibene FP, Ingbar DH, Mann HJ, Hoyt DB, Angus DC, Thomas AV Jr, Danner RL, Suffredini AF (2009) Forging a critical alliance: Addressing the research needs of the United States critical illness and injury community. Crit Care Med 37:3158-3160.

21. Gajic O, Dabbagh O, Park PK, Adesanya A, Chang SY, Hou P, Anderson H 3rd, Hoth JJ, Mikkelsen ME, Gentile NT, Gong MN, Talmor D, Bajwa E, Watkins TR, Festic E, Yilmaz M, Iscimen R, Kaufman DA, Esper AM, Sadikot R, Douglas I, Sevransky J, Malinchoc M (2010) Early identification of patients at risk of acute lung injury: evaluation of lung injury prediction score in a multicenter cohort study. Am J Respir Crit Care Med 183:462-470.

22. von Elm E, Altman DG, Egger M, Pocock SJ, Gotzsche PC, Vandenbroucke JP (2007) The Strengthening the Reporting of Observational Studies in Epidemiology (STROBE) statement: guidelines for reporting observational studies. Ann Int Med 147:573-577.

23. Knaus WA, Draper EA, Wagner DP, Zimmerman JE (1985) APACHE II: a severity of disease classification system. Crit Care Med 13:818-829.

24. Determann RM, Royakkers A, Wolthuis EK, Vlaar AP, Choi G, Paulus F, Hofstra J, de Graaff MJ, Korevaar JC, Schultz MJ (2010) Ventilation with lower tidal volumes as compared with conventional tidal volumes for patients without acute lung injury: a preventive randomized controlled trial. Crit Care 14:R1-R31.

25. Gajic O, Dara SI, Mendez JL, Adesanya AO, Festic E, Caples SM, Rana R, St Sauver JL, Lymp JF, Afessa B, Hubmayr RD (2004) Ventilator-associated lung injury in patients without acute lung injury at the onset of mechanical ventilation. Crit Care Med 32:1817-1824.

26. Aberle DR, Wiener-Kronish JP, Webb WR, Matthay MA (1988) Hydrostatic versus increased permeability pulmonary edema: diagnosis based on radiographic criteria in critically ill patients. Radiology 168:73-79.

27. Esteban A, Fernandez-Segoviano P, Frutos-Vivar F, Aramburu JA, Najera L, Ferguson ND, Alia I, Gordo F, Rios F (2004) Comparison of clinical criteria 
for the acute respiratory distress syndrome with autopsy findings. Ann Int Med 141:440-445.

28. Schwarz MI, Albert RK (2004) "Imitators" of the ARDS: implications for diagnosis and treatment. Chest 125:1530-1535.

29. National Organization for Rare Disorders 0, (Accessed December 20, 2010, at http://www.rarediseases.org/search/rdbdetail_abstract.html?disname=Acute \%20Respiratory\%20Distress\%20Syndrome.

30. Fowler AA, Hamman RF, Good JT, Benson KN, Baird M, Eberle DJ, Petty TL, Hyers TM (1983) Adult respiratory distress syndrome: risk with common predispositions. Ann Int Med 98:593-597.

31. Hudson LD, Milberg JA, Anardi D, Maunder RJ (1995) Clinical risks for development of the acute respiratory distress syndrome. Am J Respir Crit Care Med 151:293-301.

32. Ferguson ND, Frutos-Vivar F, Esteban A, Gordo F, Honrubia T, Penuelas O, Algora A, Garcia G, Bustos A, Rodriguez I (2007) Clinical risk conditions for acute lung injury in the intensive care unit and hospital ward: a prospective observational study. Crit Care 11:R96.

33. Li G, Malinchoc M, Cartin-Ceba R, Venkata CV, Kor DJ, Peters SG, Hubmayr RD, Gajic O (2011) Eight-year trend of acute respiratory distress syndrome: a population-based study in Olmsted County, Minnesota. Am J Respir Crit Care Med 183:59-66.

34. Personal communications with Drs. Michelle Gong and Ognjen Checklist for Lung Injury Prevention - CLIP., Accessed May 26, 2011, 2011 https:// ephpublic.aecom.yu.edu/clip/default.aspx.

35. Li J, Murphy-Lavoie H, Bugas C, Martinez J, Preston C (1999) Complications of emergency intubation with and without paralysis. Am J Emer Med 17:141-143.

36. Drakulovic MB, Torres A, Bauer TT, Nicolas JM, Nogue S, Ferrer M (1999) Supine body position as a risk factor for nosocomial pneumonia in mechanically ventilated patients: a randomised trial. Lancet 354:1851-1858.

37. Koeman M, van der Ven AJ, Hak E, Joore HC, Kaasjager K, de Smet AG, Ramsay G, Dormans TP, Aarts LP, de Bel EE, Hustinx WN, van der Tweel I, Hoepelman AM, Bonten MJ (2006) Oral decontamination with chlorhexidine reduces the incidence of ventilator-associated pneumonia. Am J Respir Crit Care Med 173:1348-1355.

38. Dellinger RP, Levy MM, Carlet JM, Bion J, Parker MM, Jaeschke R, Reinhart K, Angus DC, Brun-Buisson C, Beale R, Calandra T, Dhainaut JF, Gerlach H, Harvey M, Marini JJ, Marshall J, Ranieri M, Ramsay G, Sevransky J, Thompson BT, Townsend S, Vender JS, Zimmerman JL, Vincent JL (2008) Surviving Sepsis Campaign: international guidelines for management of severe sepsis and septic shock: 2008. Crit Care Med 36:296-327.

39. Rivers E, Nguyen B, Havstad S, Ressler J, Muzzin A, Knoblich B, Peterson E, Tomlanovich M (2001) Early goal-directed therapy in the treatment of severe sepsis and septic shock. The New Engl J Med 345:1368-1377.

40. Wiedemann HP, Wheeler AP, Bernard GR, Thompson BT, Hayden D, de Boisblanc B, Connors AF Jr, Hite RD, Harabin AL (2006) Comparison of two fluid-management strategies in acute lung injury. $N$ Engl J Med 354:2564-2575.

41. Gong MN, Thompson BT, Williams P, Pothier L, Boyce PD, Christiani DC (2005) Clinical predictors of and mortality in acute respiratory distress syndrome: potential role of red cell transfusion. Crit Care Med 33:1191-1198.

42. Institute for Healthcare Improvement, Accessed May 26, 2011 http://www.hi.org//HI/Topics/PatientSafety/SafetyGeneral/Tools/ SBARTechniqueforCommunicationASituationalBriefingModel.html.

43. Moss M, Bucher B, Moore FA, Moore EE, Parsons PE (1996) The role of chronic alcohol abuse in the development of acute respiratory distress syndrome in adults. Journal of the American Medical Association 50:54.

44. Selzer ML (1971) The Michigan alcoholism screening test: the quest for a new diagnostic instrument. Am J Psychiatry 127(12):1653-8.

45. Charlson M, Szatrowski TP, Peterson J, Gold J (1994) Validation of a combined comorbidity index. J Clin Epidemiol 47(11):1245-51.

46. Chobanian AV, Bakris GL, Black HR et al (2003) Seventh report of the Joint National Committee on Prevention, Detection, Evaluation, and Treatment of High Blood Pressure. Hypertension 42(6):1206-52.

47. Chobanian AV, Bakris GL, Black HR et al (2003) The Seventh Report of the Joint National Committee on Prevention, Detection, Evaluation, and Treatment of High Blood Pressure: the JNC 7 report. JAMA 289(19):2560-72

48. Hunt SA (2005) ACC/AHA 2005 guideline update for the diagnosis and management of chronic heart failure in the adult: a report of the
American College of Cardiology/American Heart Association Task Force on Practice Guidelines (Writing Committee to Update the 2001 Guidelines for the Evaluation and Management of Heart Failure). J Am Coll Cardiol 46(6):e1-82.

49. (2007) Diagnosis and classification of diabetes mellitus. Diabetes Care 30(Suppl 1):S42-S47.

50. Pauwels RA, Buist AS, Ma P, Jenkins CR, Hurd SS (2001) Global strategy for the diagnosis, management, and prevention of chronic obstructive pulmonary disease: National Heart, Lung, and Blood Institute and World Health Organization Global Initiative for Chronic Obstructive Lung Disease (GOLD): executive summary. Respir Care 46(8):798-825.

51. Expert Panel Report 3 (EPR-3) (2007) Guidelines for the Diagnosis and Management of Asthma-Summary Report 2007. J Allergy Clin Immunol 120(5 Suppl):S94-138.

52. American Thoracic Society/European Respiratory Society International Multidisciplinary Consensus Classification of the Idiopathic Interstitial Pneumonias (2002) This joint statement of the American Thoracic Society (ATS), and the European Respiratory Society (ERS) was adopted by the ATS board of directors, June 2001 and by the ERS Executive Committee, June 2001. Am J Respir Crit Care Med 165(2):277-304.

53. Sonnenberg A, Everhart JE (1997) Health impact of peptic ulcer in the United States. Am J Gastroenterol 92(4):614-20.

54. Anthony PP, Ishak KG, Nayak NC, Poulsen HE, Scheuer PJ, Sobin LH (1978) The morphology of cirrhosis. Recommendations on definition, nomenclature, and classification by a working group sponsored by the World Health Organization. J Clin Pathol 31(5):395-414.

55. K/DOQI clinical practice guidelines for chronic kidney disease (2002) evaluation, classification, and stratification. Am J Kidney Dis 39(2 Suppl 1):S1-266.

56. Levey AS, Eckardt KU, Tsukamoto Y et al (2005) Definition and classification of chronic kidney disease: a position statement from Kidney Disease: Improving Global Outcomes (KDIGO). Kidney Int 67(6):2089-100.

57. Alpert JS, Thygesen K, Antman E, Bassand JP (2000) Myocardial infarction redefined-a consensus document of The Joint European Society of Cardiology/American College of Cardiology Committee for the redefinition of myocardial infarction. J Am Coll Cardiol 36(3):959-69.

58. Thygesen K, Alpert JS, White HD (2007) Universal definition of myocardial infarction. J Am Coll Cardiol 50(22):2173-95.

59. Hirsch AT, Haskal ZJ, Hertzer NR et al (2006) ACC/AHA 2005 guidelines for the management of patients with peripheral arterial disease (lower extremity, renal, mesenteric, and abdominal aortic): executive summary a collaborative report from the American Association for Vascular Surgery/Society for Vascular Surgery, Society for Cardiovascular Angiography and Interventions, Society for Vascular Medicine and Biology, Society of Interventional Radiology, and the ACC/AHA Task Force on Practice Guidelines (Writing Committee to Develop Guidelines for the Management of Patients With Peripheral Arterial Disease) endorsed by the American Association of Cardiovascular and Pulmonary Rehabilitation; National Heart, Lung, and Blood Institute; Society for Vascular Nursing; TransAtlantic Inter-Society Consensus; and Vascular Disease Foundation. J Am Coll Cardiol 47(6):1239-312.

60. Adams HP Jr, del Zoppo G, Alberts MJ et al (2007) Guidelines for the early management of adults with ischemic stroke: a guideline from the American Heart Association/American Stroke Association Stroke Council, Clinical Cardiology Council, Cardiovascular Radiology and Intervention Council, and the Atherosclerotic Peripheral Vascular Disease and Quality of Care Outcomes in Research Interdisciplinary Working Groups: The American Academy of Neurology affirms the value of this guideline as an educational tool for neurologists. Circulation 115(20):e478-534.

61. Knopman DS, DeKosky ST, Cummings JL et al (2001) Practice parameter: diagnosis of dementia (an evidence-based review). Report of the Quality Standards Subcommittee of the American Academy of Neurology. Neurology 56(9):1143-53.

62. Karon JM, Buehler JW, Byers RH et al (1992) Projections of the number of persons diagnosed with AIDS and the number of immunosuppressed HIV-infected persons--United States, 1992-1994. MMWR Recomm Rep 41(RR-18):1-29.

63. Steinman TI, Becker BN, Frost AE et al (2001) Guidelines for the referral and management of patients eligible for solid organ transplantation. Transplantation 71(9):1189-204. 
64. Knaus WA, Wagner DP, Draper EA et al (1991) The APACHE III prognostic system. Risk prediction of hospital mortality for critically ill hospitalized adults. Chest 100(6):1619-36.

65. Calandra T, Cohen J (2005) The international sepsis forum consensus conference on definitions of infection in the intensive care unit. Crit Care Med 33(7):1538-48.

66. American College of Chest Physicians/Society of Critical Care Medicine Consensus Conference (1992) Definitions for sepsis and organ failure and guidelines for the use of innovative therapies in sepsis. Crit Care Med 20(6):864-74.

67. Antonelli M, Levy M, Andrews PJ et al (2007) Hemodynamic monitoring in shock and implications for management. International Consensus Conference, Paris, France, 27-28 April 2006. Intensive Care Med 33(4):575-90.

68. Rivers E, Nguyen B, Havstad S et al (2001) Early goal-directed therapy in the treatment of severe sepsis and septic shock. N Engl J Med 345(19):1368-77.

69. Gutierrez G, Reines HD, Wulf-Gutierrez ME (2004) Clinical review: hemorrhagic shock. Crit Care 8(5):373-81.

70. Hollenberg SM, Kavinsky CJ, Parrillo JE (1999) Cardiogenic shock. Ann Intern Med 131(1):47-59.

71. Hochman JS, Boland J, Sleeper LA et al (1995) Current spectrum of cardiogenic shock and effect of early revascularization on mortality. Results of an International Registry. SHOCK Registry Investigators Circulation 91(3):873-81.

72. Marik PE (2001) Aspiration pneumonitis and aspiration pneumonia N Engl J Med 344(9):665-71.

73. Banks PA (1997) Practice guidelines in acute pancreatitis. Am J Gastroenterol 92(3):377-86.

74. Sachdeva RC (1999) Near drowning. Crit Care Clin 15(2):281-96.

75. Bouchama A, Knochel JP (2002) Heat stroke. N Engl J Med 346(25):1978-88.

76. Voelkel NF (2002) High-altitude pulmonary edema. N Engl J Med 346(21):1606-7.

77. Derdak S (2007) Acute respiratory distress syndrome in trauma patients J Trauma 62(6 Suppl):S58.

78. Arozullah AM, Khuri SF, Henderson WG, Daley J (2001) Development and validation of a multifactorial risk index for predicting postoperative pneumonia after major noncardiac surgery. Ann Intern Med 135(10):847-57.

79. Arozullah AM, Daley J, Henderson WG, Khuri SF (2000) Multifactorial risk index for predicting postoperative respiratory failure in men after major noncardiac surgery. The National Veterans Administration Surgical Quality Improvement Program. Ann Surg 232(2):242-53.

80. Zimmerman JE, Kramer AA, McNair DS, Malila FM (2006) Acute Physiology and Chronic Health Evaluation (APACHE) IV: hospital mortality assessment for today's critically ill patients. Crit Care Med 34(5):1297-310.

81. Rubenfeld GD, Angus DC, Pinsky MR, Curtis JR, Connors AF Jr, Bernard GR (1999) Outcomes research in critical care: results of the American Thoracic Society Critical Care Assembly Workshop on Outcomes Research. The Members of the Outcomes Research Workshop. Am J Respir Crit Care Med 160(1):358-67.

82. Kleinman S, Caulfield T, Chan P et al (2004) Toward an understanding of transfusion-related acute lung injury: statement of a consensus panel. Transfusion 44(12):1774-89.

83. Toy P, Popovsky MA, Abraham E et al (2005) Transfusion-related acute lung injury: definition and review. Crit Care Med 33(4):721-6

84. McGregor JC, Rich SE, Harris AD et al (2007) A systematic review of the methods used to assess the association between appropriate antibiotic therapy and mortality in bacteremic patients. Clin Infect Dis 45(3):329-37.

85. Kumar A, Roberts D, Wood KE et al (2006) Duration of hypotension before initiation of effective antimicrobial therapy is the critical determinant of survival in human septic shock. Crit Care Med 34(6):1589-96

86. Dellinger RP, Carlet JM, Masur H et al (2004) Surviving Sepsis Campaign guidelines for management of severe sepsis and septic shock. Crit Care Med 32(3):858-73.

87. Jimenez MF, Marshall JC (2001) Source control in the management of sepsis. Intensive Care Med 27(Suppl 1):S49-62.

88. Esteban A, Anzueto A, Frutos F et al (2002) Characteristics and outcomes in adult patients receiving mechanical ventilation: a 28-day international study. JAMA 287(3):345-55.
89. Vincent $J$, Akca S, De Mendonca A et al (2002) The epidemiology of acute respiratory failure in critically ill patients $\left(^{*}\right)$. Chest 121(5):1602-9.

90. Vincent JL, Moreno R, Takala J et al (1996) The SOFA (Sepsis-related Organ Failure Assessment) score to describe organ dysfunction/failure. On behalf of the Working Group on Sepsis-Related Problems of the European Society of Intensive Care Medicine. Intensive Care Med 22(7):707-10.

91. Teasdale G, Jennett B (1974) Assessment of coma and impaired consciousness. A practical scale. Lancet 2(7872):81-4

92. Sessler CN, Gosnell MS, Grap MJ et al (2002) The Richmond AgitationSedation Scale: Validity and reliability in adult intensive care unit patients. American Journal of Respiratory and Critical Care Medicine 166(10):1338-44

93. Ely EW, Inouye SK, Bernard GR et al (2001) Delirium in mechanically ventilated patients: Validity and reliability of the Confusion Assessment Method for the intensive care unit (CAM-ICU). Journal of the American Medical Association 286(21):2703-10.

94. Rice TW, Wheeler AP, Bernard GR, Hayden DL, Schoenfeld DA, Ware LB (2007) Comparison of the SpO2/FiO2 Ratio and the PaO2/FiO2 Ratio in Patients with Acute Lung Injury or Acute Respiratory Distress Syndrome. Chest.

doi:10.1186/1865-1380-5-22

Cite this article as: Hou et al:: Towards prevention of acute lung injury: frequency and outcomes of emergency department patients at-risk - a multicenter cohort study. International Journal of Emergency Medicine 2012 $5: 22$.

\section{Submit your manuscript to a SpringerOpen ${ }^{\circ}$ journal and benefit from:}

- Convenient online submission

- Rigorous peer review

- Immediate publication on acceptance

- Open access: articles freely available online

- High visibility within the field

- Retaining the copyright to your article

Submit your next manuscript at springeropen.com 